\title{
Carbon neutral University of Eastern Finland (UEF) by 2025
}

\section{Tuulevi Ovaska}

University of Eastern Finland Library, Kuopio, Finland

\begin{abstract}
Reducing environmental barm aims to build a responsible and sustainable future. The University of Eastern Finland (UEF) promotes the United Nations' (UN) Sustainable Development Goals (SDGs) in all its operations. UEF's goal is to become carbon neutral by 2025. The Library has staff members in two of the university's six working groups that chart the carbon emissions of the university and a steering group member.
\end{abstract}

Key words: (MeSH): carbon footprint; Finland; libraries; universities.

\section{Introduction}

The University of Eastern Finland (UEF) has taken determined steps to reduce environmental harm over the past few years, for example switched to $100 \%$ renewable energy, begun carbon offsetting and recycling of consumer plastic waste at the university's campuses. The UEF strategy is rooted in global challenges and aims to build a responsible and sustainable future. The UEF has agreed to promote the United Nations' Sustainable Development Goals (UN SDGs) in all its operations. Sustainability and responsibility are also the key development principles for university campuses. The university has signed the Society's Commitment to Sustainable Development as part of the implementation of the Sustainable Development Agenda 2030 in Finland and adheres to SDGs through our Green Office and Fairtrade agreements.

\section{Becoming carbol neutral by 2025}

In accordance with its Climate Action Plan, the university is committed to taking action to mitigate the effects of climate change with the goal of the university becoming carbon neutral by 2025. The university has calculated its carbon footprint this year, and concrete measures to reduce it are being planned accordingly. Through its strategy for 2021-2033, the UEF builds a responsible and sustainable future. UEF ranked 67th in the UI Green Metric World University
Ranking comparing a total of 780 universities (1). UI Green Metric Ranking compares universities based on how well they take environmental responsibility and sustainable development into consideration in their activities.

A kick-off event of the Carbon Neutral UEF 2025 project was held on the 4 th of June 2020. The UEF appointed working groups to chart the carbon emissions of its facilities, procurements, travel, restaurant services and laboratories - and to brainstorm ideas on how to reduce them - and scholarly communication that promotes carbon neutrality. Besides the university's own experts, the working groups have stakeholder representatives. The library has a staff member, an information specialist from the collection services, in the procurement working group. The procurement working group has made numerous calculations of the carbon footprint and produced suggestions on how to reduce it. This includes the library's acquisitions, e.g., the carbon footprint of printed books and journals has been studied. As a coordinator of the library's communications, I am a member of the communication group. The tasks of this working group include increasing the visibility of sustainable development both on the website and the intranet of the UEF, increasing the transparency of the actions, inspiring the staff and the students to eco-acting, creating campaigns, making the aims more concrete,

Address for correspondence: Tuulevi Ovaska, University of Eastern Finland Library, Yliopistonranta 1, FI-70210 Kuopio, Finland. E-mail: tuulevi.ovaska@uef.fi 
building a website for sustainable development at the UEF, visualising the aims and achievements, and reporting the outcomes of the project. In addition, the project has a coordination group and a steering group in which the library has a member from the Internal Services.

\section{Conclusions}

In Finland, the Unifi, a co-operational organisation for Finnish universities that promotes higher education, research and arts by addressing far-reaching, university related issues and aims to influence the Finnish higher education and research policy, has just published 12 theses on sustainable development and responsibility. (2).
Submitted on invitation. Accepted on 25 November 2020.

\section{REFERENCES AND LINKS}

1. Overall rankings 2019 [Internet]. UI Green Metric. [cited 2020 Nov 25]. Available from: http://greenmetric.ui.ac.id/overall-rankings-2019/

2. Theses on sustainable development and responsibility [Internet]. Unifi. [cited $2020 \mathrm{Nov}$ 25]. Available from:

https://www.unifi.fi/viestit/theses-on-sustainabledevelopment-and-responsibility/ 